Cómo citar este artículo / Referencia normalizada

N Lorite García, J Grau Rebollo, J de Sousa Lacerda (2018): "Representación de la diversidad sociocultural en la publicidad audiovisual: materiales para un tratamiento inclusivo". Revista Latina de Comunicación Social, 73, pp. 425 a 446.

http://www.revistalatinacs.org/073paper/1263/22es.html

DOI: $10.4185 /$ RLCS-2018-1263

\title{
Representación de la diversidad sociocultural en la publicidad audiovisual: materiales para un tratamiento inclusivo
}

\author{
Representation of sociocultural diversity in audiovisual \\ advertising: materials for inclusive treatment
}

\begin{abstract}
Nicolás Lorite García [ $[\underline{\mathrm{CV}}]$ Universitat Autònoma de Barcelona (D) Jorge Grau Rebollo [ $\underline{\mathrm{CV}}]$ Universitat Autònoma de Barcelona $(\mathrm{D}) \mathrm{G}$-jordi.grau@uab.cat Juciano de Sousa Lacerda [CV] Universidade Federal do Río Grande do Norte, Brasil (D) juciano.lacerda@gmail.com
\end{abstract}

\begin{abstract}
s
[ES] Introducción: Nuestro objetivo es analizar el tratamiento que le otorga la publicidad audiovisual a la diversidad sociocultural, centrándonos particularmente en los rasgos fenotípicos. Proponemos también algunas líneas de actuación orientadas hacia las buenas prácticas dinamizadoras de la interculturalidad inclusiva, previniendo la reproducción de supuestos racistas o xenófobos. Metodología: hemos basado nuestro análisis en: (a) una muestra general de 834 anuncios publicitarios emitidos en franja de prime time en diversas televisiones del Estado español, (b) entrevistas en profundidad a 38 especialistas, (c) el trabajo conjunto con diversas asociaciones profesionales y organismos institucionales y (d) un estudio de recepción con 249 estudiantes universitarios. Resultados: concluimos que la diversidad fenotípica en la publicidad está infrarrepresentada con respecto a la realidad social de referencia y que las buenas prácticas inclusivas deben pasar por incorporar la diversidad multicultural en la publicidad televisiva. Subrayamos la importancia de hacerlo desde perspectivas dinamizadoras interculturales que muestren discursos con interconexiones interpersonales e intergrupales, en diferentes contextos y situaciones.
\end{abstract}

[EN] Introduction: Our objective is to analyze the treatment that audiovisual advertising makes of sociocultural diversity, focusing particularly on phenotypic traits. We also propose some lines of action oriented towards good dynamizing practices in inclusive intercultural milieus, avoiding the reproduction of racist or xenophobic assumptions. Methodology: we have based our analysis on: (a) a general sample of 834 advertisements broadcasted in prime time on various Spanish television channels, (b) in-depth interviews with 38 advertising experts, (c) collaborative work with various professional associations and institutional organizations, and (d) a reception study with 249 college students. Results: we conclude that phenotypic diversity in advertising is underrepresented with respect to the social reality of reference and that inclusive good practices must go through the 
incorporation of multicultural diversity in television advertising. We emphasize the importance of doing it from intercultural dynamizing perspectives that show discourses with interpersonal and intergroup interconnections in different contexts and situations.

\section{Keywords}

[ES] Diversidad sociocultural; Publicidad televisiva; Buenas prácticas inclusivas; Investigación audiovisual aplicada; Interculturalidad.

[EN] Sociocultural diversity; TV advertising; Good inclusive practices: Applied audiovisual research; Intercultural environments.

\section{Contens}

[ES] 1. Introducción. 2. Metodología y conceptos de referencia. 2.1. Criterios de inclusión. 2.2. Procedimiento de muestreo. 3. Análisis y resultados. 3.1. El protagonismo de la diversidad en el anuncio. 3.2. interacciones y procesos de dinamización interculturales. 3.3. Prácticas publicitarias inclusivas: selección de ejemplos. 3.4. Del análisis de la emisión al de la producción y la recepción. 4. Conclusiones y recomendaciones para la práctica publicitaria inclusiva. 5. Notas 6. Referencias bibliográficas.

[EN] 1. Introduction. 2. Methods and concepts of reference. 2.1 Inclusion criteria. 2.2. Sampling procedure. 3. Analysis and results. 3.1. The prominence of diversity in the spot. 3.2. Interactions and processes of intercultural dynamization. 3.3. Inclusive advertising practices: selection of examples. 3.4. From the analysis of broadcast to the production and reception analysis. 4. Conclusions and recommendations for inclusive advertising practices. 5 Notes 6 . List of references.

Traducción de resumen de Jordi Grau Rebollo

(Doctor en Antropología Social, Universitat Autònoma de Barcelona)

Traducción de artículo de Yuhanny Henares

(Traductora académica, Universitat de Barcelona)

\section{Introducción}

¿Cuál es el tratamiento que le otorga la publicidad audiovisual (televisiva) a la diversidad sociocultural y en particular a los protagonistas de fenotipos diferentes a los predominantes blancos/caucásicos centroeuropeos de nuestro entorno? Y ¿cuál puede ser el más adecuado para evitar los efectos racistas y xenófobos y dinamizar la convivencia intercultural? Son preguntas que intentamos responder, desde el 2012, mediante diferentes proyectos en los que venimos investigando la representación audiovisual de la diversidad sociocultural, principalmente fenotípica, desde equipos interdisciplinares, compuestos por investigadores de diferentes áreas del conocimiento (Comunicación, Antropología, Educación, Lingüística y Política) para ampliar al máximo los puntos de vista de un objeto de estudio tan sumamente polisémico como éste, desde modelos de investigación-acción e investigación audiovisual aplicada, consistentes en vincular la Academia con el Aula, y ambas a su vez, con la realidad sociomediática, en concreto con las instituciones, organizaciones y colectivos que la representan como pueden ser el Colegio de Publicitarios y Relaciones Públicas de Catalunya, la Asociación de Empresarios de la Publicidad o la Mesa por la Diversidad en el Audiovisual del Consejo del Audiovisual de Catalunya, además de las agencias y empresas del sector de la publicidad, interesadas por incorporar la diversidad sociocultural a sus campañas. 
Partimos de una metodología multimodal de análisis de los spots publicitarios, destinada a obtener el máximo de referencias objetivas, cuantitativas y cualitativas desde cuatro ejes fundamentales del análisis de los discursos audiovisuales: emisión, producción, recepción y dinamización. En este texto mostramos los resultados más relevantes y algunos ejemplos significativos con ciertas pistas audiovisuales para comprender como aborda la publicidad el tratamiento inclusivo y representa de manera igualitaria y ética las diversidades culturales y fenotípicas, residentes en las sociedades receptoras de migraciones internacionales donde circulan los mensajes publicitarios analizados.

\section{Metodología y conceptos de referencia}

\subsection{Criterios de inclusión}

Para seleccionar adecuadamente la publicidad con diversidad y verificar si es inclusiva debemos establecer una doble consideración preliminar: por un lado, la propia noción de "diversidad" y, por otro, su distinción de conceptos como "diferencia" y "desigualdad". Toda sociedad es al mismo tiempo similar y heterogénea y se reconoce a sí mismo como tal en función de un substrato cultural compartido. Así, al tratar con las diferencias apreciables en los spots, trabajamos con la manifestación de rasgos morfológicos (fenotipo) que, aun formando parte de la conformación particular y única de esa persona, suelen extrapolarse a la delimitación y clasificación de grupos culturales en función de su apariencia, con todas las consecuencias que esto puede conllevar (Boulton 2015; Shankar 2015; Bristor et al. 1995).

Entre los efectos más perniciosos de esta clasificación podemos encontrar la lectura de grupos culturales en términos de desigualdad en función de sus características fenotípicas (Jindra, 2014). En esta línea algunos estudios en España han orientado su atención hacia la frecuencia de representación de determinados colectivos (minorías éticas, inmigrantes) en series de ficción, reflexionando acerca de su posible incidencia en los fenómenos de inclusión o de antialteridad concurrentes en la sociedad española (Marcos et al., 2014; Marcos Ramos \& Igartúa Perosanz, 2014; Baladrón Pazos, 2011).

Por consiguiente, el fenotipo de las personas seleccionadas para formar parte de un spot es relevante tanto en lo que se refiere a la dimensión empresarial -etnomarketing- (Gaona Pisonero \& Martínez Pastor, 2008) como en la eventual proactividad de su rol como facilitadores o normalizadores de la integración social de dichos colectivos (Arroyo Almaraz \& Martín Nieto, 2009; Gaona et al., 2016).

Para detectar la publicidad inclusiva hay que partir de la selección, codificación y análisis de muestras objetivas (Ibáñez, 1998) de spots, difundidos en medios como el televisivo [1], en horarios de prime time, con un seguimiento e impacto importante de los mensajes por parte de las audiencias plurales. Partimos, por tanto, del análisis de la emisión de una muestra objetiva de anuncios, seleccionada durante un periodo concreto, establecido de acuerdo con un número limitado de variables que nos permitan detectar de manera cuantitativa, inicialmente, el total de anuncios con diversidad. Esta será la muestra que tomemos como referencia para profundizar en el análisis cualitativo de la representación de la diversidad y su tratamiento inclusivo desde diferentes especialidades narrativas audiovisuales.

Pero ¿cómo diferenciamos la publicidad con diversidad (principalmente fenotípica) de la que no lo es? y ¿en qué nos basamos para considerarla inclusiva? Para diferenciarla partimos de un concepto de publicidad audiovisual inclusiva que permita evaluar el tratamiento de la diversidad en los anuncios seleccionados. Es importante subrayar que dicho concepto se establece a partir del debate interdisciplinar (epistemológico, teórico y metodológico) inicial en el que cada investigador, del equipo interdisciplinar configurado, aporta su visión particular de acuerdo con las escuelas de pensamiento de referencia en su área de conocimiento (Grau, 2016; Bonin, Lorite García y Maldonado, 2016; Lorite García, 2004, 2006 y 2011), pero con el objetivo principal de extraer el concepto de los conceptos para no extralimitarse a emular o tomar como propias teorías experimentadas con temas similares en otros momentos y contextos, recogiendo en ese sentido lo que 
recomienda Ibáñez al respecto de la necesidad de articular un marco de referencia teórico propio, acotado a la espacio-temporalidad del objeto de estudio (Ibáñez, 1998).

Una de las primeras distinciones conceptuales van destinadas a saber diferenciar el anuncio publicitario inclusivo de la buena práctica publicitaria. Buena práctica es la que trata a todos los protagonistas del anuncio de la misma manera porque constatamos que no discrimina a ninguno de ellos sea cual sea su fenotipo, color de piel o supuesto origen. Asimismo, verificamos que se ejecutan los mismos encuadres o planos con todos los protagonistas y se les otorga el mismo valor narrativo en función del tamaño o posicionamiento de la cámara (Millerson, 1993; Gubern, 1987). Pero dicho tratamiento igualitario es además inclusivo si el spot muestra cómo interactúan los protagonistas de distintas identidades y fenotipos, y lo hacen mediante modelos de comunicación e interconexión interculturales activos que son capaces de suscitar los mismos procesos dinamizadores interculturales entre los receptores/consumidores plurales del mensaje publicitario. Por tanto, la buena práctica guarda relación con una representación equilibrada de los diferentes fenotipos, en función de los diferentes elementos textuales, gráficos y audio y/o visuales del discurso publicitario, pero será inclusiva, además, si se los muestra efectuando actos comunicativos, verbales y no verbales, e interconexiones (estructurales y/o coyunturales), capaces de suscitar las mismas dinámicas interculturales inclusivas de los receptores plurales del mensaje.

Con todo, difícilmente encontraremos una publicidad totalmente inclusiva. Para ello hemos de constatar que además de reunir los requisitos anteriores, la banda sonora (voz, música, efectos y silencio) codifique desde idénticos parámetros las diversas identidades representadas en la pieza y permita ser decodificada desde una recepción multicultural como apunta Muraca (2012 y 2013). Lo mismo hemos de preguntarnos con relación a otros elementos del discurso audiovisual como son: los escenarios con su respectiva iluminación (¿muestran de manera equilibrada y no estereotipada los espacios o contextos en los que actúan los personajes diversos?), el diseño gráfico (¿guardan relación la tipografía y el color únicamente con referentes occidentales? como constata Entenza (2016)), u otros elementos relativos a las dimensiones y estéticas de los cuerpos y vestimentas de los personajes. Es muy importante también verificar el ritmo del montaje audiovisual, observando si concuerda con los diferentes tiempos y ritmos vitales predominantes de cada cultura o se decanta por un solo ritmo, propio de los modelos urbanos de clase media acomodada a los que nos pretende trasladar el consumo de los productos anunciados.

Desde la metodología multimodal y los modelos de investigación-acción e investigación audiovisual aplicada, en los que se encuadra este estudio, consideramos que es conveniente partir también de las recomendaciones recogidas por los manuales de estilo o códigos deontológicos en uso. Ante todo, algo que hemos verificado es que no hay ningún manual específico sobre publicidad y diversidad sociocultural en los diferentes ámbitos mediáticos analizados (España y Cataluña) así como sí es posible encontrarlo es otros sectores de la comunicación como el de la información [2] Los diferentes manuales y códigos que abordan en algunas de sus propuestas la representación de la diversidad fenotípica, cultural y étnica, coinciden en defender un tratamiento igualitario de los diferentes protagonistas del mensaje. Se propone que todos los personajes sean representados, respetando al máximo su realidad cotidiana, evitando posibles efectos discriminatorios. Asimismo, se recomienda no acudir a los estereotipos y evitar la asociación de los rasgos físicos con los superficiales y distorsionadores tópicos culturales que detentamos sobre los supuestos orígenes geográficos de los actores. Sobre esto José Carlos Sendín y Patricia Izquierdo recomiendan: "construir discursos más mesurados y representativos de la comunidad inmigrante que los sitúe en el escenario social como un actor más" (Sendín e Izquierdo, 2008: 27). 
También es posible encontrar alguna recomendación a propósito del tratamiento adecuado de la diversidad en la publicidad en los códigos que usan organizaciones reguladoras del sector en España como Autocontrol (Asociación para la Autorregulación de la Comunicación Comercial), donde se advierte explícitamente que: "La publicidad no sugerirá circunstancias de discriminación ya sea por razón de raza, nacionalidad, religión, sexo u orientación sexual, ni atentará contra la dignidad de la persona" (Autocontrol, 2011: 4).

\subsection{Procedimiento de muestreo}

Como la muestra objetiva inicial, obtenida desde la perspectiva de la emisión, es la base de todo el proceso posterior de análisis multimodal audiovisual desde la producción, recepción y dinamización, hemos de establecer inicialmente un concepto universal que nos permita cuantificar y comparar adecuadamente las piezas publicitarias con criterios de homogeneidad (García Ferrando, Ibáñez y Alvira, 1998; García Ferrando, 1984). Para ello, hemos manejado exclusivamente el de spots normal de marca (también denominado para nuestro estudio unidad publicitaria televisiva -UPTV-), dejando de lado tipologías publicitarias como los patrocinios, la teletienda, la autopublicidad y los publirreportajes. Ello permite seleccionar piezas publicitarias audiovisuales de una duración determinada $(5,10,20,30,40,45$ y hasta 60 segundos o más), difundidas entre la programación informativa, divulgativa y de entretenimiento de las cadenas de televisión (Infoadex, 2013; Lorite García, 2016).

Un primer indicador cuantitativo sobre representación de la diversidad sociocultural en la publicidad televisiva lo obtenemos de una muestra de spots de la televisión privada generalista: Tele5, Antena 3, La Sexta y Cuatro (descartamos TVE por tener prohibida la emisión de publicidad comercial), agregando la cadena pública autonómica catalana TV3 no únicamente por el hecho de disponer de referencias de una región con porcentajes importantes de residentes extranjeros, sino sobre todo debido a que la emisión audiovisual en Cataluña está explícitamente supervisada por una autoridad independiente de regulación de la comunicación audiovisual (el Consejo Audiovisual de Cataluña, CAC [3]). Entre los órganos creados por el CAC destaca la Mesa para la Diversidad en el Audiovisual, algunos de cuyos objetivos se orientan a: "Reflexionar sobre la representación de la diversidad cultural en los medios audiovisuales" y a "Elaborar propuestas dirigidas al sector audiovisual para colaborar a la mejor promoción de los valores de la diversidad" [4]. Entre los resultados más recientes de su actividad figura una investigación específicamente orientada a analizar la publicidad audiovisual y la diversidad sociocultural en Cataluña (MDA-CAC, 2015).

Tabla 1. Total de spots de marca, tiempos de emisión y porcentaje de pantalla.

\begin{tabular}{|c|c|c|c|c|}
\hline $\begin{array}{c}\text { Cadena } \\
\text { de tv }\end{array}$ & Spots & $\begin{array}{c}\text { Tiempo de publicidad } \\
\text { emitida en segundos }\end{array}$ & $\begin{array}{c}\text { Tiempo de publicidad emitida } \\
\text { en horas, minutos y segundos }\end{array}$ & $\begin{array}{c}\text { Porcentaje de } \\
\text { pantalla }\end{array}$ \\
\hline Antena 3 & 857 & 15.055 & $4: 10: 55$ & $14,94 \%$ \\
\hline Cuatro & 1.204 & 21.707 & $6: 01: 47$ & $21,53 \%$ \\
\hline La Sexta & 837 & 14.240 & $3: 57: 20$ & $14,13 \%$ \\
\hline Tele5 & 935 & 16.471 & $4: 34: 31$ & $16,34 \%$ \\
\hline TV3 & 794 & 15.626 & $4: 20: 26$ & $15,50 \%$ \\
\hline TOTAL & 4.627 & 83.099 & $23: 04: 59$ & $16,49 \%$ \\
\hline
\end{tabular}

Fuente: diseño propio.

Una vez seleccionadas las cadenas televisivas, elegimos un horario amplio de prime time (las tres horas que van de las 20,30 a las 00,30 horas), durante la semana del lunes 17 de marzo al domingo 23 de marzo 2014, periodo anual alejado de las campañas navideñas y de otras promociones o campañas prevacacionales o de rebajas. Seguidamente se redactó un libro de códigos donde se definieron y 
operacionalizaron cada una de las variables que se tuvieron en cuenta en la codificación. Así, se grabaron en total 140 horas de publicidad televisiva, correspondientes a más de cuatro mil seiscientos spots de marca o UPTVs (tabla 1) que se distribuyeron por cadenas televisivas y de acuerdo con los siguientes porcentajes y tiempos de emisión.

Tras un primer proceso de codificación se descartaron 371 piezas, correspondientes a autopromociones de la propia cadena, patrocinios u otras formas de publicidad sobreimpresionada en la programación, al no ser consideradas spots de marca o unidades publicitarias televisivas (UPTV). De los 4.256 anuncios restantes se depuró una primera muestra que recogía todos aquellos anuncios no repetidos que incluían personajes en su realización de 834 unidades publicitarias televisivas en total. Sobre esta primera muestra se operó una clasificación exhaustiva en función de diversas variables (canal de televisión, año, mes, día, duración de la pieza en segundos, sinopsis, idioma y anunciante diferenciando grupo empresarial, marca y producto -, así como el número de anuncios de la campaña). A continuación, se procedió a la identificación de personajes con rasgos apreciables de diversidad de acuerdo con el criterio principal del fenotipo de los personajes, pero teniendo en cuenta también otros elementos como el idioma, la indumentaria o los escenarios del anuncio. Esta última agrupación constituyó la segunda muestra de 65 spots de marca o UPTVs que es la que nos permite obtener un porcentaje indicativo de publicidad televisiva con diversidad del 7,8\% (sobre la muestra de 834) que podemos evaluarlo como insuficiente si tenemos en cuenta referencias como la de los porcentajes de población extranjera residente en España en el 2014, situados en torno al 15\% (IDESCAT, 2016).

De cada uno de estos 65 spots con diversidad se identificó a los 359 personajes (principal, secundario o incidental) que aparecían en ellos para su posterior codificación individual. De entre ellos, se trabajó especialmente con los 128 protagonistas que presentaban rasgos apreciables de diversidad. Se extrajo primero el storyboard, con los planos principales del anuncio (en función del encuadre), y su sincronía con los planos sonoros. Se codificaron dos aspectos fundamentales a considerar para verificar si se trata de una propuesta de publicidad inclusiva como son el protagonismo desempeñado y las interacciones (estructurales y/o coyunturales, jerárquicas o igualitarias), así como los procesos de dinamización intercultural que se observan en el anuncio y pueden causar en la recepción plural del mensaje publicitario. Consideramos oportuno codificar además otras referencias como género, franja etaria, complexión, estatura, nivel socioeconómico, contexto social, color de piel, color de ojos, color de pelo, tipo de cabello e indumentaria, como referencias complementarias al análisis cualitativo de cada personaje, pero no con fines estadísticos, mediante cruzamientos de variables, de acuerdo a lo que recomiendan Miles \& Huberman (1994) y Martínez (2008).

$\mathrm{Si}$, como decíamos, la selección de piezas publicitarias audiovisuales que conforma nuestro repertorio muestral se ha llevado a cabo en base a criterios objetivos de emisión, algunas categorías y variables de análisis de la submuetra de personajes (e.g. color de piel o franja etaria) responden a criterios de consenso y, consiguientemente, subjetivos. De hecho, cualquier análisis cualitativo probablemente incluirá un componente subjetivo en la configuración de categorías de análisis como las que aquí manejamos, por la sencilla razón de que no responden a clasificaciones aleatorias o a procedimientos estandarizados de operacionalización. Así, por ejemplo, cuando optamos por construir agrupaciones de edad necesitamos establecer delimitaciones operativas entre ellas que posibiliten la posterior comparación controlada entre los datos codificados en la muestra. Obviamente, la clasificación resultante puede variar en función del criterio de delimitación que se elija, aunque estos cortes sean necesarios para conformar categorías de edad relativamente comparables entre las fuentes estadísticas y el análisis audiovisual. Insistimos en el carácter relativo inherente a este tipo de comparación puesto que es fácil, por ejemplo, recabar ciertos datos de las series detalladas de cifras de población recopiladas por el Instituto Nacional de Estadística, pero es del todo punto imposible obtener magnitudes de semejante precisión en la publicidad audiovisual emitida por televisión. 
Por consiguiente, como señala Galeano (2004), debe tenerse en cuenta este grado de subjetividad a la hora de considerar los datos de la investigación; pero como puntualizan Álvarez-Gayou (2003) y Ruiz Olabuénaga (2012), asumirlo no implica renunciar a su potencial heurístico en la medida que asume que nuestra experiencia "está condicionada por nuestra adopción de una perspectiva previa a ella" (Ruiz Olabuénaga, 2012: 272) que logra una comprensión crítica de las cosas mediante procesos de reflexión, puesta en común y crítica colectiva (ídem, p. 275).

En este sentido, manejamos categorías y variables cuya operacionalización es fruto de un consenso determinado con la firme determinación de llevar a cabo un análisis riguroso de las mismas, pero con la cautela de advertir que cualquier modificación de las mismas condicionaría la extrapolación de los resultados (como ocurre, por otro lado, con cualquier análisis que tome la clase social como base, por ejemplo).

\section{Análisis y resultados}

\subsection{El protagonismo de la diversidad en el anuncio}

El repertorio muestral analizado nos permite constatar ciertas referencias significativas para sugerir una publicidad inclusiva. Una primera fundamental es la del protagonismo de los actores de fenotipos, color de piel y demás rasgos considerados, distintos en la publicidad televisiva española. Para diferenciar adecuadamente su papel en la pieza publicitaria tenemos en cuenta los tres papeles habituales que suelen desempeñar el cuadro de actores de cualquier producto audiovisual: principal, secundario e incidental. Todo relato audiovisual publicitario suele diferenciar un número muy limitado de actores principales, a veces solamente uno o dos, que nos lo muestran en primer plano y sobre los que recae la responsabilidad de sostener el hilo narrativo de la trama argumental. También aparecen otros actores secundarios, durante algunas secuencias y escenas, complementando la actuación de los principales. Una tercera tipología es la de los personajes incidentales, según denomina Martínez (2005): sólo actúan algún instante, y en el caso de los relatos publicitarios apenas se les puede percibir de manera visual porque permanecen como máximo un segundo del total de duración de la pieza publicitaria. Mediante esta clasificación procuramos conocer cuál es el protagonismo de los personajes de fenotipos diferentes a los autóctonos en los spots con diversidad, y con ello intentamos comprender si desempeñan los mismos papeles y si su tratamiento es igualitario y dinamiza la interculturalidad, de acuerdo al concepto de publicidad audiovisual inclusiva que defendemos, o si se les relega a papeles secundarios o incidentales.

Tabla 2. Protagonismo de la diversidad sociocultural en los spots con diversidad.

\begin{tabular}{|c|c|c|c|}
\hline Protagonistas & Otros fenotipos & Blanco-caucásicos & Total \\
\hline Principal & $54(28.4 \%)$ & $136(71.6 \%)$ & $190(100 \%)$ \\
\hline Secundario & $45(37.2 \%)$ & $76(62.8 \%)$ & $121(100 \%)$ \\
\hline Incidental & $29(60.4 \%)$ & $19(39.6 \%)$ & $48(100 \%)$ \\
\hline Total & $128(35.6 \%)$ & $231(64.4 \%)$ & $359(100 \%)$ \\
\hline
\end{tabular}

Fuente: MIGRACOM-UAB.

Un primer dato significativo es que, de los 359 personajes, 231 (64.4\%) son de rasgos que podríamos considerar autóctonos o blanco-caucásicos y 128 (35.6\%) de fenotipos y demás rasgos como el color de piel que cabe asociar con otros orígenes e identidades (africanos, latinoamericanos o asiáticos). Si bien este primer dato general ya demuestra que el protagonismo de los anuncios con diversidad no recae en protagonistas diversos, aún queda más claro al constatar que de los 190 personajes de los 359 
$(52,9 \%)$ que desempeñan un papel principal, 136 (71.6\%) son autóctonos o blanco-caucásicos y tan sólo $54(28.4 \%)$ de otros fenotipos o identidades. Dichas proporciones van invirtiéndose conforme tenemos en cuenta los personajes secundarios e incidentales. No obstante, en el caso de los protagonistas secundarios las proporciones siguen decantándose claramente aun hacia los autóctonos $(62.8 \%)$, y el $37.2 \%$ son de otros orígenes. Con los incidentales se invierte totalmente la tendencia: $39.6 \%$ son blanco-caucásicos y $60.4 \%$ de otros fenotipos, según recoge la tabla.

\subsection{Interacciones y procesos de dinamización interculturales}

Otra manera de evaluar el tratamiento inclusivo de la publicidad es constatando si interactúan entre sí los protagonistas de los distintos fenotipos e identidades que aparecen en el anuncio y si dicha relación es equilibrada o igualatoria, o por el contrario discriminatoria o jerárquica. A partir de ahí comprobamos si dicha comunicación verbal y no verbal, interpersonal y/o intergrupal, puede suscitar procesos de dinamización interculturales inclusivos en la pluralidad de receptores o potenciales consumidores multiculturales de los productos anunciados. Para verificarlo codificamos las interacciones de los personajes de acuerdo con dos tipologías: a) coyunturales o en base a criterios subjetivos de gradación (como por ejemplo hombres/mujeres en relación con capacidades o facultades intelectuales, foráneo/autóctono en relación con nociones de autoridad moral, etc.); b) estructurales o en función del contexto (es el caso del director/empleado en el puesto de trabajo, médico/paciente en una consulta hospitalaria, policía/transeúnte en la regulación de la movilidad urbana, etc.). Asimismo, tenemos en cuenta cuándo no interactúan y si ello obedece únicamente al tipo de montaje audiovisual publicitario (mediante transiciones por corte capaces de separar los planos de cada protagonista) o al protagonismo otorgado. A continuación, codificamos si dicha comunicación es igualitaria o discriminatoria y el tipo de dinamización intercultural que puede suscitar.

Tabla 3. Interconexiones de los protagonistas de los spots con diversidad.

\begin{tabular}{|l|c|c|c|}
\hline Interacciones & $\begin{array}{c}\text { Otros } \\
\text { fenotipos }\end{array}$ & Blanco-caucásicos & $\begin{array}{c}\text { Total } \\
\text { agregado }\end{array}$ \\
\hline Coyunturales & 20 & 27 & 47 \\
& $15.6 \%$ & $11.7 \%$ & $13.1 \%$ \\
\hline Estructurales & 49 & 53 & 102 \\
\hline Estructurales & $38.3 \%$ & $22.9 \%$ & $28.4 \%$ \\
y coyunturales & 20 & 47 & 67 \\
Total & $15.6 \%$ & $20.3 \%$ & $18.7 \%$ \\
\hline interacciones & $\mathbf{8 9}$ & $\mathbf{1 2 7}$ & $\mathbf{2 1 6}$ \\
\hline No se dan & $\mathbf{6 9 . 5 \%}$ & $\mathbf{5 4 . 9 \%}$ & $\mathbf{6 0 . 2 \%}$ \\
\hline No interactúan por el montaje (transición por corte) & 16 & 17 & 33 \\
& $12.5 \%$ & $7.4 \%$ & $9.2 \%$ \\
\hline $\begin{array}{l}\text { Total } \\
\text { interacciones más } \\
\text { no interacciones }\end{array}$ & 23 & 87 & 110 \\
\hline
\end{tabular}

Fuente: MIGRACOM-UAB.

Del total de 359 personajes codificados, extraídos de las 65 unidades publicitarias con diversidad, podemos constatar que el $69.5 \%$ de los "otros" fenotipos e identidades (en concreto 89 del total de 128) suelen interactuar con los demás personajes autóctonos (231) mediante algún tipo de relaciones coyunturales $(15.6 \%)$, estructurales $(38.3 \%)$ o ambas (15.6\%), según recoge la tabla siguiente. Eso quiere decir que tres de cada diez $(30.5 \%)$ no interactúan con los demás, debido a que no se propicia en el relato publicitario $(12.5 \%)$ o por el tipo de montaje mediante transiciones visuales por corte 
(18.0\%). Los protagonistas autóctonos interactúan menos que los de los otros fenotipos (54.9\%), y se usa mucho más con ellos el recurso de mostrar un sólo protagonista en un plano: $37.7 \%$, con los otros fenotipos tan sólo se ejecuta con el 18\%. Ello obedece a que se trata de modelos de anuncios en el que los personajes principales son destacados en un solo plano al principio y final del spot y suelen ser principalmente autóctonos o blanco-caucásicos, tal y como hemos constatado en el apartado anterior.

Para comprobar si esas interconexiones de los protagonistas de diferentes identidades son inclusivas o discriminatorias tenemos en cuenta, además, el tipo de relación igualitaria o jerárquica que se da entre ellos. Pero como ello no es posible cuantificarlo mostramos a continuación como lo analizamos, desde la perspectiva cualitativa, con algunos de los ejemplos más significativos, extraídos conforme a criterios como el de máxima difusión e impacto de las unidades publicitarias con diversidad de la muestra analizada.

\subsection{Prácticas publicitarias inclusivas: selección de ejemplos}

Uno de los ejemplos en los que se da un tipo de interconexión estructural o en un mismo espacio o escenario, en este caso, entre los personajes, es el del spot de la empresa 11.822 de consultas telefónicas. Vemos a una mujer de otro fenotipo cantando en el coro (ver ilustración 1) como un miembro más. En el plano seleccionado no se observa ninguna relación jerárquica ni discriminatoria. Puede tratarse de una buena práctica publicitaria porque se le otorga un mismo tratamiento a esta protagonista que al resto de componentes de diferentes rasgos físicos al suyo. Dicho tratamiento puede ser considerado además inclusivo porque puede suscitar la misma normalización de la comunicación intercultural entre los receptores del mensaje.

\section{Ilustración 1. Imagen seleccionada del story-board de 11822.}

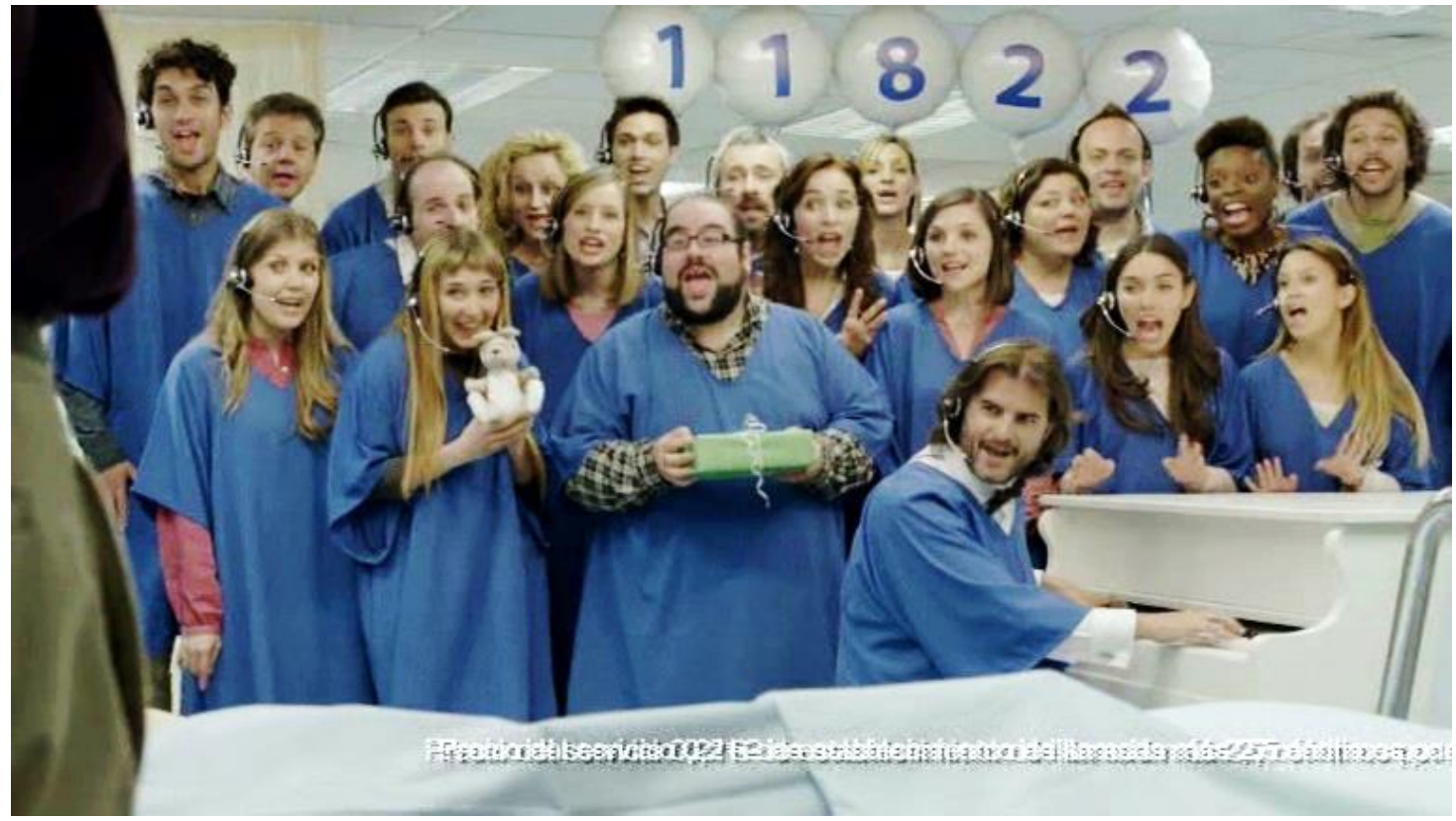

Fuente: MIGRACOM-UAB.

El anuncio también tiene en cuenta la igualdad de género (hay 11 hombres y 11 mujeres), incluso las diversidades de tamaño corporal, tipo de cabello, estatura, edad y hasta diferentes rasgos físicos de los personajes de un mismo color de piel. Aun así, se trata de un coro de góspel atípico. Habitualmente suelen ser todos los cantantes de piel negra y origen afroamericano. No obstante, teniendo en cuenta que el ámbito de recepción del mensaje es la sociedad española una mejor representación fenotípica, 
acorde con la realidad multicultural, pasaría por incorporar algún protagonista más de otro fenotipo (tal vez un hombre) y ubicar a la mujer de piel negra en los puntos de máximo interés del cuadro (de acuerdo con la regla de los tercios), en la primera fila, y desempeñando un rol principal como sería el de tocar el piano.

Uno de los spots con diversidad de la muestra va destinado a recordar el Día Mundial del Síndrome de Down. En este caso se da un tipo de interacción principalmente coyuntural porque interactúan personas de diferentes roles. Al igual que en el anuncio anterior todos los personajes cantan y bailan juntos. Se trata de un ejemplo de publicidad inclusiva porque muestra las diversidades, no solo las fenotípicas sino también las funcionales (denominadas aun como minusvalías o discapacidades), interactuando con total normalidad entre ellas e invitando a los receptores del mensaje a participar de manera activa en la campaña con su baile y canción. Es un claro exponente de mensaje publicitario que puede suscitar el mismo proceso de dinamización intercultural inclusivo. Uno de los protagonistas principales es el hombre del plano medio de la siguiente ilustración.

\section{Ilustración 2. Plano del anuncio sobre el Dia Mundial del Síndrome de Down.}

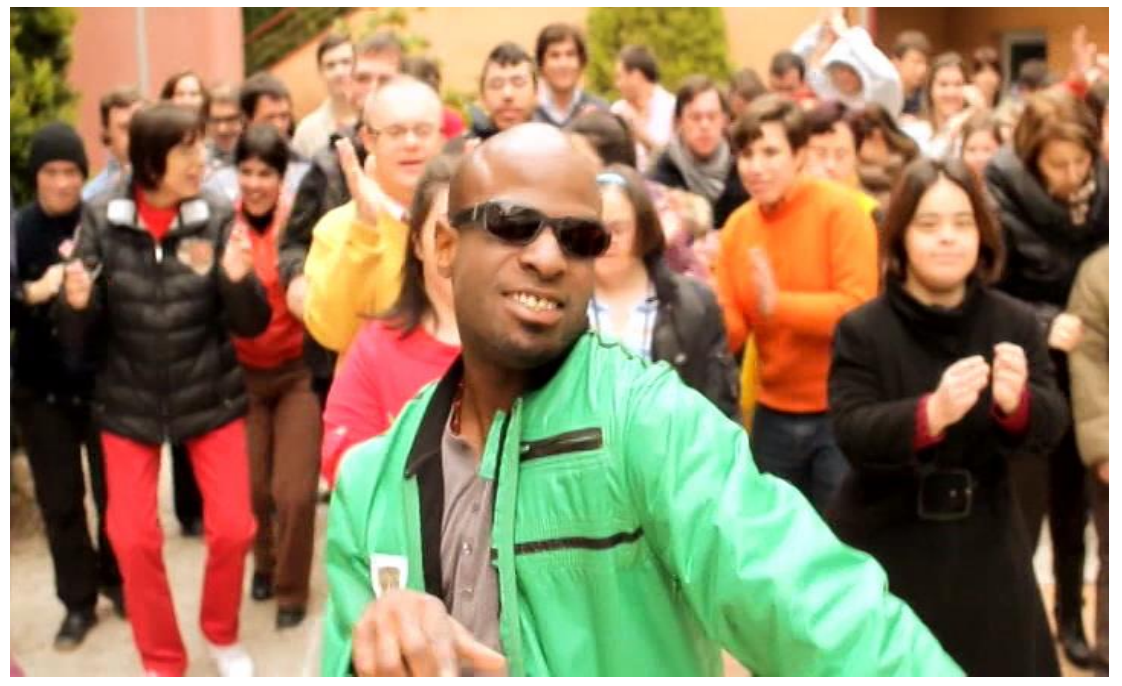

Fuente: MIGRACOM-UAB.

La campaña de San Miguel, empresa de cerveza española, es otro ejemplo de práctica publicitaria inclusiva, dinamizadora de la interculturalidad, en la que podemos observar todo tipo de interconexiones (coyunturales y estructurales) entre los protagonistas de diversos fenotipos y orígenes, sin que se observe ningún tipo de relación jerárquica ni discriminadora entre ellos. En la muestra analizada obtuvimos dos spots, uno de 60 segundos y otro de 40, en los que podemos ver cómo interactúan personas de distintos fenotipos y orígenes geográficos, interpretando, mediante diferentes estilos musicales, una misma canción (A Place Called World), titulada de la misma manera que el eslogan de la campaña: "Un lugar llamado mundo" y que emplaza a un modelo de convivencia global entre todas las culturas del mundo.

En este caso es importante destacar la perspectiva de la producción y el compromiso de la marca con la normalización de la diversidad. Forma parte de los objetivos del anunciante. La marca ha querido crear "una oda a la mezcla y a la unión de todos los ciudadanos del mundo"[5]. Se trata de un spot producido con el apoyo de la agencia SCPF de Barcelona, en la que trabajan publicitarios y creativos como Toni Segarra, que defienden este tipo de propuestas interculturales e inclusivas, según manifestó en la entrevista realizada para este estudio. 
RLCS, Revista Latina de Comunicación Social, 73 - Páginas 425 a 446 [Investigación] [Financiada] DOI: 10.4185/RLCS, 73-2018-1263| ISSN 1138-5820| Año 2018

Ilustración 3. Selección de imágenes del storyboard de la campaña "Un lugar llamado mundo" de la campaña de San Miguel (60").

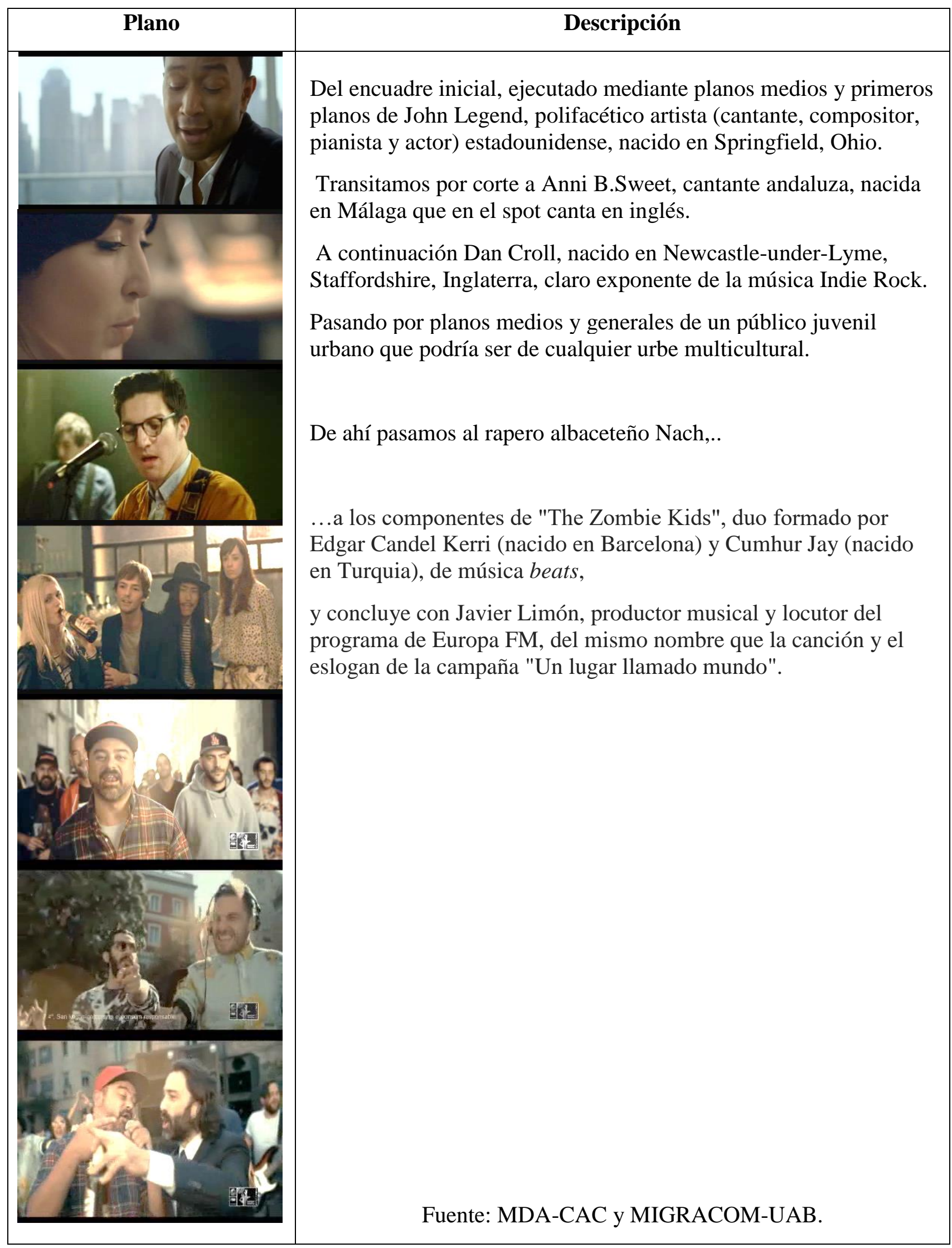


El spot de Carolina Herrera, anunciando su producto 212 VIP, podría tratarse de un tipo de publicidad que si bien tiene en cuenta la diversidad parece relegarla a ese segundo plano de personajes secundarios e incidentales que aguardan en la puerta, y que unos guardias de seguridad se encargan de "vigilar" para que dejen pasar a la élite VIP, representada por dos personajes principales, hombre y mujer, aparentemente top models, de rasgos occidentales y del color de piel que podemos ver en la ilustración siguiente, muy distinta al del hombre que aparece en la primera imagen en el centro del cuadro:

\section{Ilustración 4. Selección de planos del story-board de 212 VIP.}

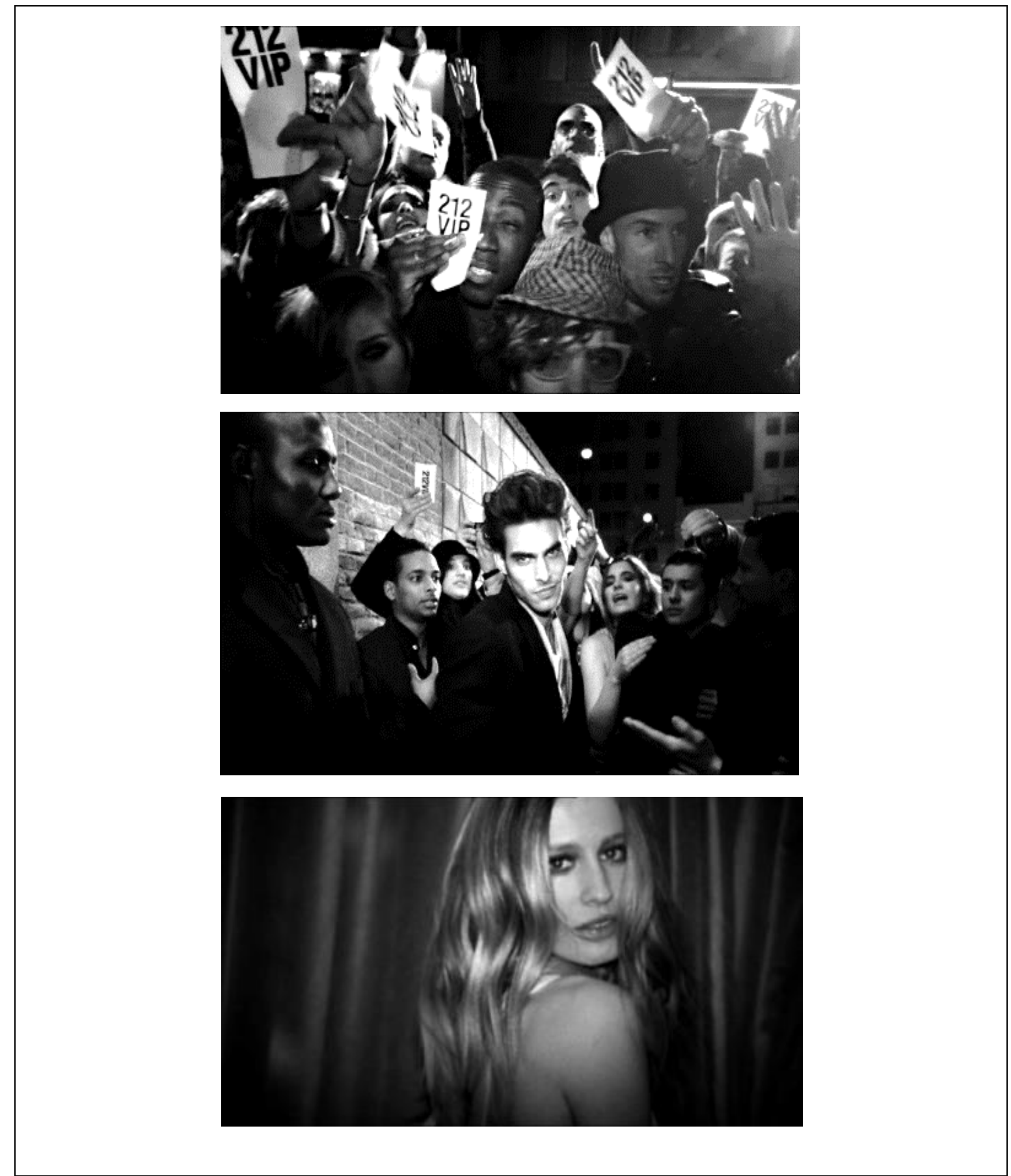

Fuente: MIGRACOM-UAB. 


\subsection{Del análisis de la emisión al de la producción y la recepción}

Uno de los ejemplos en los que no se da ninguna comunicación entre los personajes, porque los planos de cada uno se asocian mediante transiciones por corte es el de la campaña de Norit. Consideramos que esta pieza incluye diversidad fenotípica porque constatamos que aparece la mujer de la ilustración 5. Se trata de una protagonista secundaria, con cabello y color de piel, diferentes al resto, que aparece en los segundos 10 y 11 , justo a la mitad, de los 20 segundos que dura el anuncio. El tratamiento visual es similar a los demás actores. No obstante, llama la atención la sincronía audiovisual. Mientras la vemos ajustándose el vestido, mediante el plano tres cuartos o americano de la ilustración 5 , se escucha la voz en off, en un registro de español estándar, que afirma: “... su color, su forma...", al compás de las notas (de un tipo de música clásica y extradiegética) de un único instrumento, un piano, que acompaña toda la pieza en segundo o primer plano sonoro.

\section{Ilustración 5. Plano del story-board de Norit.}

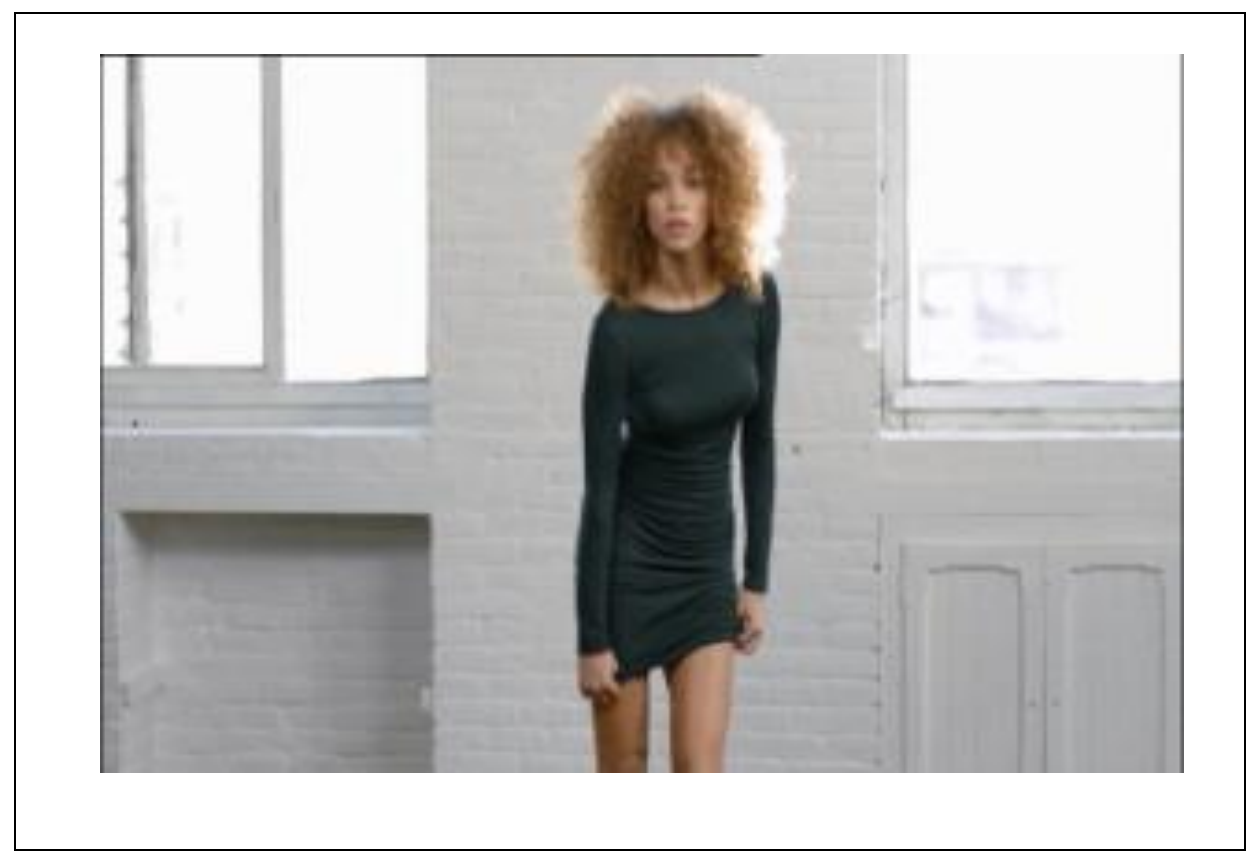

Fuente: MIGRACOM-UAB

Dicha sincronía podríamos considerarla poco apropiada porque resalta solo esos dos aspectos de un fenotipo como ese que puede destacar por ambas condiciones, pero vemos que se usa también con los demás actores. Previamente el off asocia la palabra "marca" con la mujer del vestido rojo, indumentaria que parece ser más de marca o etiqueta que la deportiva del único hombre que aparece en el anuncio.

También podemos observar que los escenarios y entornos del spot se decantan por los colores poco saturados y luminosos y su aspecto general es algo gris y oscuro y por lo tanto propio de ciertos ambientes urbanos de ciudades históricas occidentales desarrolladas. Pero lo que llama la atención de dicho tratamiento cromático y musical es que suele asociarse con entornos de clases medias en las que predomina el fenotipo homogéneo que aparece representado en casi todo el anuncio, salvo cuando aparece la mujer de fenotipo distinto en el núcleo de la trama narrativa.

No obstante, llegados a este punto del análisis audiovisual cualitativo consideramos oportuno verificar nuestra perspectiva subjetiva del análisis de contenido desde la producción real del anuncio. Conviene recordar que realizamos nuestra investigación desde propuestas de investigación-acción e investigación audiovisual aplicada, destinadas a descubrir y proponer prácticas publicitarias inclusivas. Por ello defendemos la objetividad que otorga la multimodalidad metodológica, procurando reunir el máximo de 
informaciones desde la perspectiva de la producción de los mensajes publicitarios (en este caso de las agencias de publicidad, de casting, las productoras audiovisuales, así como desde los equipos de comunicación de las empresas anunciantes y las instituciones y organizaciones que desempeñan un papel fundamental en la normalización de la diversidad en la publicidad y de la diversidad en general) [6].

\section{Ilustración 6. Planos del story-board de Norit.}

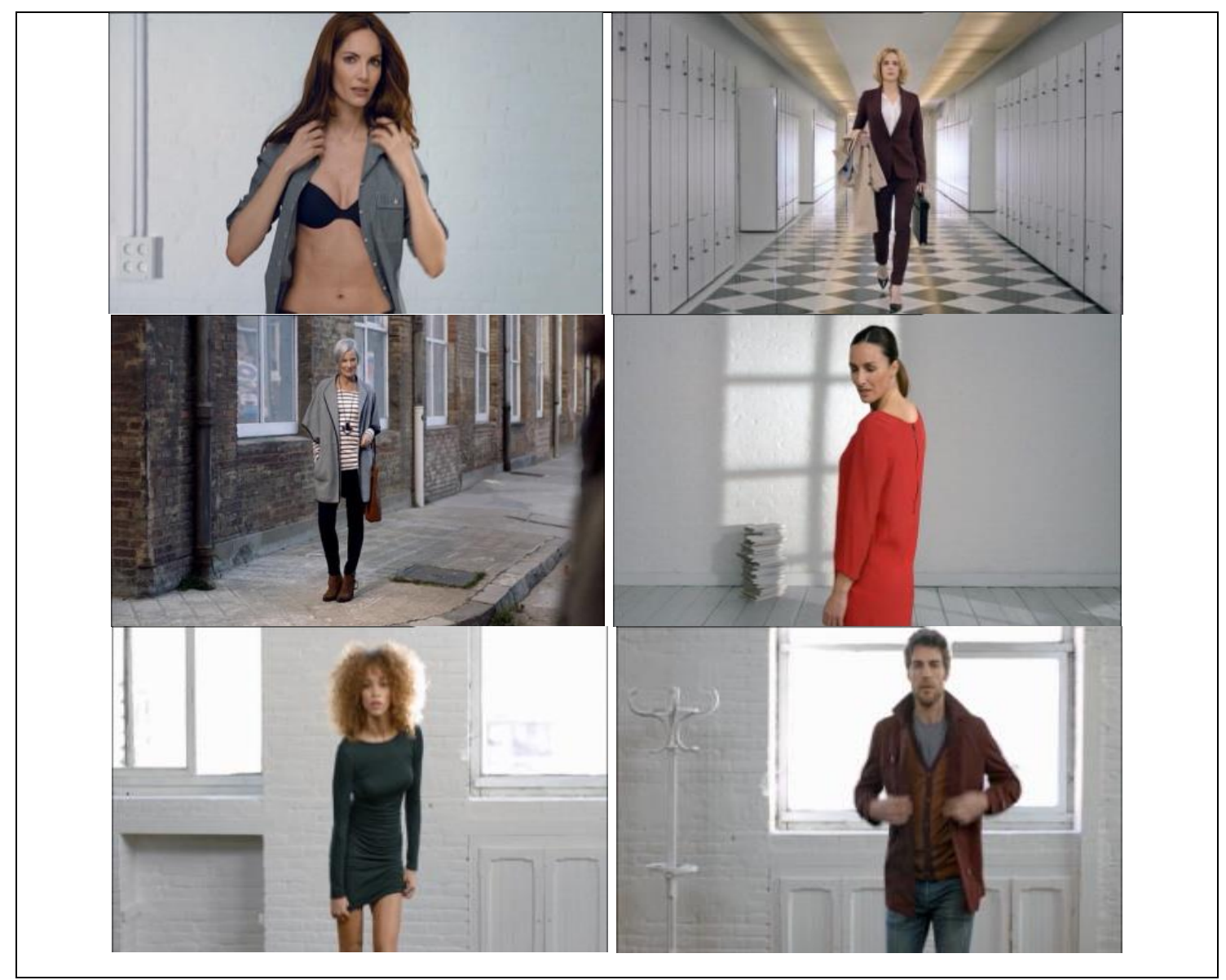

Fuente: MIGRACOM-UAB

Uno de los especialistas seleccionados, Xavi Sitjar, director de la agencia Paradise Falls y creativo del anuncio de la campaña de Norit, consideró que: “[...] incorporábamos a una chica mulata [porque] [...] en este anuncio hablábamos mucho de la diversidad de ropa, de las diferentes prendas que usamos en el día a día, la diversidad de colores, esa diversidad forma parte del patrimonio de la marca". Por su parte, Jordi Picas, creativo de la agencia y de la campaña, argumentó que con ello se pretende transmitir la idea de que:

"[...] nuestro producto Norit lava la ropa de una forma o concibe la ropa de una forma diferente, no es solo lavar por lavar, sino que oye, entiendo que tú te has gastado tu tiempo, te has gastado tu dinero en buscar un tipo de ropa que transmite tus valores...".

Con todo, no se trata de una diversidad omnipresente:

"francamente me ha costado percibir una extraordinaria muestra de diversidad sobre todo porque aparecen bastantes tipologías y todos son caucásicas tradicionales, si es verdad que la segunda vez que lo ves descubres que hay una chica un poquito más diversa ¿no?” (Toni Segarra, publicitario) 
Aunque, como señala Joan Rión (director de la agencia de Casting Vadever): "[...] en este caso Norit ha apostado por la diversidad... ha abierto un poco el abanico de personajes". Esta apuesta no está exenta de riesgos, en la medida que las marcas miden con tiento cada elección que afecte a la imagen final que puede asociarse a la empresa a través del spot que se genera [7]: "la agencia podrá dar una idea equis creativa pero el que dice que si o que no es el anunciante, el que se arriesga es el anunciante o el que tiene miedo a arriesgarse es el anunciante" (José Ángel Abancens, Publicitario y Presidente de la Asociación de Empresarios de la Publicidad). Y todo ello, "no solo porque la marca es la que pone el dinero y la que pone el riesgo sino porque es la que pone finalmente la audacia" (Toni Segarra, publicitario, agencia SCPF).

Así, existe cierto consenso entre los profesionales publicitarios en la idoneidad de una publicidad con personajes fenotípicamente diversos (color de piel, complexión, altura...), pero también en reconocer las limitaciones que puede llegar a imponer el cliente por temor a las consecuencias que para su negocio puede tener una elección que la audiencia considere desacertada. Pero también existe un factor relevante en este sentido: el contexto sociodemográfico real en el que se inserta dicha audiencia:

"yo creo que no hay ninguna mala intención en ello, sino que simplemente son los grandes olvidados. Creo que a medida que este grupo de personas que conviven con nosotros, de otras culturas, de otras razas, a medida que vayan adquiriendo poder económico, peso económico en nuestra sociedad se irán incorporando en las diferentes campañas de las marcas [...] Quizás en otras sociedades que hace cien años que se han incorporado personas de diferentes culturas no son vistos como extranjeros [...] Para nosotros son nuevos y quieras que no ,,la sociedad aun los considera que son extranjeros, que no son de aquí" (Ton del Pozo, decano del Colegio de Publicitarios y Relaciones Públicas de Catalunya).

Y en no pocas ocasiones la realidad pone de manifiesto el peso de nuestros propios sesgos. Desde el estudio de la emisión codificamos de manera subjetiva a esta mujer como protagonista de fenotipo diferente, pero desde el estudio de la producción se nos matiza y hasta descompone bastante dicha interpretación: "[...] sé que ella originariamente vive aquí en Barcelona y sé que ella tiene orígenes británicos, con lo cual supongo que tendrá orígenes africanos entiendo, pero si yo entiendo que eso podrían ser parte de sus orígenes, pueden venir de África" (Xavi Sitjar).

Finalmente, cabe preguntarse: ¿Cómo es percibido el fenotipo de la mujer de Norit por distintos segmentos de audiencia y cómo reaccionan ante la construcción narrativa audiovisual de la diversidad? Respondemos a esta pregunta desde una tercera perspectiva del análisis multimodal: la del estudio de la recepción y dinamización de la representación de la diversidad en la publicidad. Para ello pudimos llevar a cabo un estudio específico en España y en Brasil [8] entre 249 estudiantes de universidades españolas (85,54\%) y brasileñas $(14,45 \%)$. Uno de los principales objetivos que perseguíamos fue analizar el impacto que tiene la publicidad sobre la realidad mediante el efecto de sus estrategias narrativas y discursivas en un sector del ámbito educativo (estudiantes). Para ello, diseñamos esta aproximación edu-investigadora como un recurso educativo de gran valor potencial mediante el trabajo con spots como el de Norit. (Lorite García y Grau Rebollo, 2017).

Esta incorporación del alumnado a la reflexión sobre la representación de la diversidad fenotípica en la publicidad televisiva permitió apreciar que el Aula también es diversa a nivel interpretativo, pese a cierta recurrencia en la asociación de algunos fenotipos con determinados orígenes étnicos y geográficos. En este sentido, no deja de resultar llamativo que los participantes atribuyan siempre un origen foráneo a los personajes seleccionados, descartando de antemano la posibilidad de que alguno pudiese ser catalán o español como es el caso de la actriz del spot de Norit. 
Tales conexiones ideológicas operan también al nivel de las nociones subjetivas de normalidad (Shankar, 2015). Así, por ejemplo, es revelador que hasta diecisiete participantes identificasen un color determinado con un tono «normalizado» de piel (refiriéndose a él como: "color carne", "color de piel", "color da pele", "tonalidad normal", etc.). Esta relevancia no viene dada tanto por su peso estadístico sobre el total de la muestra (sólo constituían el 9\%) como por lo que permite intuir acerca de la existencia de patrones referenciales de base a este respecto, (Shankar, 2015; Baladrón, 2011).

Así, preguntados acerca de si consideraban el tratamiento de la diversidad que apreciaban en unidades publicitarias como la de Norit, como un ejemplo de práctica publicitaria inclusiva, encontramos en nuestro estudio que los factores más recurrentes a la hora de conferir a un spot dicha condición se asociaban a las manifestaciones explícitas de diversidad en lo referente a edad y sexo/género, así como a la variedad de apariencias y perfiles sociodemográficos percibidos en el marco de un mismo spot. Por el contrario, la caricaturización se manifiesta como el umbral de tolerancia de un estereotipo; esto es: el punto a partir del cual la distorsión ideológica (siempre a partir de una disposición física evidente) se considera denigrante $u$ ofensiva.

\section{Conclusiones y recomendaciones para la práctica publicitaria inclusiva}

Agregamos a estas conclusiones las recomendaciones porque no sólo pretendemos resumir lo más significativo, sino destacar, tal y como reza en el título y hemos expuesto a lo largo del texto, cuáles pueden ser algunos elementos para una publicidad audiovisual (televisiva) inclusiva:

1. Según hemos mostrado, toda propuesta inclusiva emerge de los resultados cuantitativos y análisis cualitativos, obtenidos al aplicar una metodología de análisis multimodal que se nutre, ante todo, de muestras objetivas de spots. Es necesario articular la crítica del discurso publicitario a partir de esta abstracción inicial para no derivar únicamente hacia el análisis crítico de las malas prácticas de representación de la diversidad que circulan por las redes sociales y acabar considerando que toda la publicidad está estereotipada y por lo tanto es racista y xenófoba.

2. Para no interpretar la publicidad desde nuestra perspectiva subjetiva e ideológica -aunque estamos de acuerdo con Ruiz Olabuénaga (2012) en el carácter inevitable de cierto componente subjetivo y en su potencial valor heurístico- hay que establecer conceptos teóricos que permitan evaluarla de manera objetiva como el de publicidad audiovisual (televisiva) inclusiva. Semejante "obsesión" por la objetividad (Chalmers, 2000) guarda relación con los modelos de investigación-acción e investigación audiovisual aplicada que articulamos para vincular la Academia con el Aula y ambas a su vez con la realidad multicultural, en particular con organizaciones e instituciones que cuidan de que no se discriminen las minorías en los mensajes publicitarios.

3. Hemos podido constatar que la publicidad televisiva con diversidad apenas tiene en cuenta la diversidad sociodemográfica real y que cuando la incorpora los protagonistas principales siguen siendo autóctonos blancos/caucásicos. Los protagonistas de fenotipos asociados con otros continentes (africanos, latinoamericanos o asiáticos) representan principalmente papeles secundarios o incidentales, como ha podido constatarse también en estudios orientados al ámbito de la ficción televisiva (Marcos

4. et al,

5. 2014). Cabe proponer una mayor participación de la diversidad fenotípica en los spots, aunque hay que hacerlo desde perspectivas dinamizadoras interculturales capaces de mostrar interacciones personales y grupales, estructurales y coyunturales, en diferentes contextos y situaciones, en igualdad de condiciones, como la de los ejemplos mostrados (11822, Día Mundial del Síndrome de Down y San Miguel).

6. La participación de "los otros" en la publicidad audiovisual (televisiva) es inclusiva si muestra y fomenta la comunicación intercultural y no suscita la discriminación clasista, racista y xenófoba. Hemos visto como se logra cuando se les otorga el mismo tratamiento visual o mismos planos o 
encuadres a todos los personajes de la pieza seleccionada. Pero también se observa como elementos del discurso publicitario tan importantes como el color y la música siguen siendo monoculturales (propios de la cultura española, europea u occidental tradicional) y no multiculturales (Martínez Corcuera, 2005; Muraca, 2013). En el anuncio de Norit escuchamos un piano, pero no una flauta andina. Predominan tonos grises pero no amarillos ni rojos.

7. Aplicando las recomendaciones de Sendín e Izquierdo (2008), hemos mostrado como la interpretación de la publicidad desde el estudio de la emisión o análisis de contenido de los spots hay que contrastarlo desde la producción y la recepción para interpretar correctamente las identidades y abordarlas desde los matices que requiere para dictaminar adecuadamente sobre la publicidad inclusiva. A veces nos vemos obligados a sintetizar la denominación de los protagonistas para poder agregar los datos y llevar a cabo su interpretación cuantitativa, pero es evidente que la mediatización de la diversidad hay que interpretarla de la misma manera heterogénea, para poderla investigar de acuerdo con su propia denominación y sin caer en ciertos sesgos reduccionistas cuantitativistas.

8. Consideramos que habría que hacer un seguimiento periódico, mediante nuevas muestras y análisis multimodales, para comprender los posibles cambios de la reproducción de la diversidad fenotípica en la publicidad, a partir de los cambios demográficos que se pueden ir sucediendo en sociedades receptoras de migraciones como la española, y tras algunos primeros pasos concienciadores en este sentido que se vienen dando con las instituciones encargadas de dinamizar la publicidad inclusiva (Mesa por la Diversidad en el Audiovisual del CAC, Colegio de Publicitarios y Relaciones Públicas de Catalunya o Asociación de Empresarios de la Publicidad). Para ello deberían tenerse más en cuenta las características sociodemográficas de los segmentos de audiencia y los contextos de recepción de los mensajes.

9. Y, por último, es conveniente advertir que hemos procurado predicar con el ejemplo y hemos cuidado al máximo los calificativos empleados para denominar a los diferentes personajes analizados. No obstante, hemos visto que a veces no queda más remedio que saltarse la norma y nombrar a los personajes blanco-caucásicos de esta manera para poderlos diferenciar adecuadamente de los que no detentan estos rasgos, que acabamos denominando inadecuadamente "otros" fenotipos. A veces no basta con usar tan sólo el nombre neutro de personaje con todos los actores. No obstante, el análisis audiovisual permite ahorrarse a veces el calificativo textual, porque ya viene dado con la imagen. La vemos diferente y dejamos que cada cual le atribuya su calificativo, que cada cual denomine la diversidad de acuerdo con su manera de entenderla o interpretarla. Este es un reto importante para aplicar a la producción publicitaria audiovisual inclusiva pero también para el conocimiento científico y en especial para una investigación audiovisual aplicada pendiente de no estereotipar el análisis científico de los estereotipos.

- Este artículo se ha realizado a partir de los datos obtenidos en los siguientes proyectos de investigación: (1) Estudio multimodal de la representación de la diversidad en la publicidad española y efectos interculturales en las ciudades del Mediterráneo en tiempos de crisis, financiado por el MINECO (CSO2012-35771); (2) Publicitat audiovisual i diversidad sociocultural a Catalunya. Materials per a un tractament inclusiu: ¿estereotips, llenguatge, imatge, gènere $i$ valors, para la Mesa por la Diversidad en el Audiovisual (MDA) del Consejo del Audiovisual de Catalunya (CAC); (c) Publicidad, propaganda, alteridad y ciudadanía: estrategias transmetodológicas de análisis de la diversidad en contextos de cambio económico y social en Brasil y España, subvencionada por CAPES (Brasil) y el Ministerio de Educación, Cultura y Deportes de España (HPB1400030). 


\section{Notas}

1 Esta ha sido la propuesta desde los primeros estudios que venimos realizando desde el MIGRACOM-UAB, desde mediados de los 90, de investigación-acción e investigación audiovisual aplicada, sobre el tratamiento de la inmigración, las minorías y la diversidad sociocultural en los medios de comunicación e información.

2 "No nos lo habíamos planteado y probablemente no se lo plantean ni las agencias, ni los clientes, tampoco habíamos hablado en el Col-legi hasta que vosotros desde el MIGRACOM nos expresasteis esta preocupación..." (Entrevista a Ton del Pozo, decano del Colegio de Publicitarios y Relaciones Públicas de Catalunya).

3 https://www.cac.cat/index.jsp.

4 https://www.cac.cat/web/mesa/index.jsp?NjM\%3D\&Mg\%3D\%3D\&L3dlYi9tZXNhL29iamVjdG $11 \mathrm{c} 0 \mathrm{NvbnRlbnQ} \% 3 \mathrm{D}$.

5 Recuperado el 25 de noviembre de 2017, de: http://www.lascancionesdelatele.com/2014/07/cancion-anuncio-san-miguel-2014.html y http://www.anuncioshd.com/2014/07/cancion-anuncio-san-miguel-2014un.html\#ixzz4ZQyoGVhs

6 Seleccionamos una muestra de un total de 38 especialistas, utilizando la cámara de video como herramienta principal de la investigación audiovisual aplicada que pretende ser también una manera científica de mostrar los resultados de la investigación (Lorite García y Grau Rebollo, 2013), entre ellos: Toni Segarra (agencia SCPF), Joaquin Lorente (publicitario, fundador de MMLB), Miquel Campmany (director de marketing y comunicación de Nestlé), Mireia Verdú (directora de la agencia de modelos Francinamodels), Joan Rión (director de casting de Vadever), Ton del Pozo (decano del Colegio de Publicitarios y Relaciones Públicas de Cataluña), José Ángel Abancens (presidente de la Asociación de Empresarios de la Publicidad y vicepresidente de la Academia de la Publicidad), Richard Wakefield (fundador de Publicitarios Implicados), Salvador Alsius (miembro del Consejo del Audiovisual de Catalunya), Carme Figueres (presidenta de la Mesa por la Diversidad en el audiovisual del CAC), Beatriu Guarro (presidenta de SOS Racismo Cataluña) y Rafael Besolí (responsable de Comunicación del Programa BCN Interculturalidad).

7 "Cuando uno se encarga y se responsabiliza de desarrollar la comunicación de una marca es entender que la publicidad habla por el producto" (Joaquín Lorente, publicitario).

8 Destinado al Estudio multimodal de la representación de la diversidad en la publicidad española y efectos interculturales en las ciudades del Mediterráneo en tiempos de crisis), para el MINECO (CSO2012-35771).

\section{Referencias bibliográficas}

J.L. Álvarez-Gayou (2003): Cómo hacer investigación cualitativa.Fundamentos y metodología, México D.F.: Paidós Mexicana 
I. Arroyo Almaraz y R. Martín Nieto (2009): "Creatividad e investigación en la publicidad dirigida al colectivo inmigrante: la senda de la integración”, en Comunicación y Hombre, 5. Editorial Universidad Francisco de Vitoria, páginas 119 a 128; recuperado el 10 de febrero de 2017, de http://www.redalyc.org/articulo.oa?id=129412636009

AUTOCONTROL (2011): Código de conducta publicitaria.

http://www.autocontrol.es/pdfs/cod_conducta_publicitaria.pdf.

J.A. Baladrón Pazos (2011): "Publicidad para inmigrantes en España. Un estudio desde las agencias", en Revista Latina de Comunicación Social, 66. La Laguna (Tenerife): Universidad de La Laguna, páginas 350 a 375; recuperado el 15 de septiembre de 2017, de http://www.revistalatinacs.org/11/art/937_Molino/RLCS_art937.pdf - DOI: http://doi.org/10.4185/RLCS - 66 - 2011 - 937 - 350 - 375.

J. Bonin; N. Lorite García y A. Maldonado (orgs) (2016): Publicidad, propaganda y diversidades socioculturales. Quito: CIESPAL.

C. Boulton (2015): "Under the cloak of whiteness: A circuit of culture analysis of opportunity hoarding and colour-blind racism inside US advertising internship programs", en Triple C, 13(2). University of Westminster: Westminster Institute for Advanced Studies, páginas 390 a 403; recuperado el 24 de noviembre de 2017, de https://www.scopus.com/inward/record.uri?eid=2-s2.0$\underline{84943272115 \& \text { partnerID=40\&md5=2a0c903c35e64e9e4cd2ff43bcee815. }}$.

J.M. Bristor, R.G. Lee y M.R. Hunt (1995): "Race and ideology: African-American images in television advertising", en Journal of Public Policy \& Marketing, 14(1). Chicago: University of Chicago, páginas 48 a 59; recuperado el 20 de abril de 2017, de http://www.jstor.org/stable/30000378

A. Chalmers (2000): ¿Qué es esa cosa llamada ciencia? Madrid: Siglo XXI de España editores.

A. Entenza (2016): "La representación de la diversidad sociocultural en la publicidad: la selección de los colores para productos audiovisuales". En J. Bonin, N. Lorite García y A. Maldonado (2016): Publicidad, propaganda y diversidades socioculturales. Quito: CIESPAL.

M.E.Galeano (2004): Diseño de proyectos en la investigación cualitativa Medellín: Universidad EAFIT: Fondo editorial.

C. Gaona, E. Martínez y R. Vizcaíno-Laorga (2016): "La comunicación institucional-intercultural en el espacio público madrileño: una nueva categoría socio-antropológica en construcción”, en Barataria. Revista Castellano Manchega de Ciencias Sociales, 12. Toledo: Asociación CastellanoManchega de Sociología, páginas 37 a 46; recuperado el 20 de enero de 2017, de https://revistabarataria.es/web/index.php/rb/article/view/128/128 DOI: http://doi.org/http://dx.doi.org/10.20932/barataria.v0i12.128

C. Gaona Pisonero y E. Martínez Pastor (2008): "La presencia Ethnic en la Publicidad Institucional", en IC: Revista Científica de Información y Comunicación, 5. Sevilla: Universidad de Sevilla, páginas 326 a 375; recuperado en 27 de febrero de 2017, de http://icjournal-ojs.org/index.php/ICJournal/article/view/271/268 
M. García Ferrando (1984): Socioestadística. Introducción a la estadística en sociología. Madrid: Centro de Investigaciones Sociológicas.

M. García Ferranco, J. Ibáñez y F. Alvira (1998): El análisis de la realidad social. Métodos y técnicas de investigación. Madrid: Alianza Universidad, segunda edición revisada y ampliada.

J. Grau Rebollo (2016): "La representación de la diversidad en la publicidad televisiva en España. Una aproximación desde la Antropología Social y Cultural”. En J. Bonin, J., N. Lorite García, N. y A. Maldonado (2016): Publicidad, propaganda y diversidades socioculturales. Quito: CIESPAL.

R. Gubern (1987): La mirada opulenta. Exploración de la iconosfera contemporánea. Barcelona: Gustavo.Gili.

J. Ibáñez (1998): Nuevos avances de la investigación social. Barcelona: Proyecto A Ediciones, segunda edición aumentada.

Idescat, Institut d'Estadistica de Catalunya (2015): Evolución de la población total y extranjera. Generalitat de Catalunya. https://www.idescat.cat/poblacioestrangera/?b=0\&lang=es.

Infoadex (2013): Estudio Infoadex de la inversión publicitaria en España 2013. Madrid: Infoadex.

Mesa para la Diversidad en el Audiovisual [MDA-CAC] (2016): Publicitat audiovisual i diversidad sociocultural a Catalunya. Materials per a un tractament inclusiu: estereotips, llenguatge, imatge, gènere $i$ valors. Consell Audiovisual de Catalunya. Informe interno. https://www.cac.cat/web/mesa/index.jsp?NjI\%3D\&MQ\%3D\%3D\&

M. Jindra (2014): “The Dilemma of Equality and Diversity", en Current Anthropology, 3(0). Chicago: University of Chicago, páginas 316 a 334; recuperado el 30 de marzo de 2017, de http://www.journals.uchicago.edu/doi/pdfplus/10.1086/676457

DOI: http://doi.org/10.1086/676457

N. Lorite García (2004): "Cómo miran los medios la inmigración y transmiten la diversidad". Diálogo 'Comunicación y Diversidad Cultural'. Fórum Universal de las Culturas. Barcelona, 2004.

N. Lorite García (2006): ¿Puede ser científica y objetiva la mirada audiovisual de la realidad migratoria? En M. Lario, (Coord.) Médios de comunicación e inmigración. Murcia: Programa CAM encuentro.

N. Lorite García (2011): Informative Treatment of Immigration and Intercultural Dynamics of Spanish Mass Media. En I. Ureta, (Ed.) Media, Migration and Public Opinion: Myths and Prejudices and the Challenge of Attaining Mutual Understending between Europe and North Africa. Bern, Berlin, Bruxelles, Frankfurt, New York, Oxford, Wien: Peter Lang.

N. Lorite García (2016): La cámara como principal herramienta para la investigación audiovisual de los procesos de dinamización intercultural mediatizados. Intexto, 34. Porto Alegre (Brasil):

Universidade Federal do Rio Grande do Sul, páginas 178 a 199

N. Lorite García y J. Grau Rebollo (2013): Investigación audiovisual de las migraciones y el 
tratamiento de la diversidad en los medios de comunicación. Un estudio de caso. En A. Granados Martínez (Ed.), Las representaciones de las migraciones en los medios de comunicación. Madrid: Trotta.

N. Lorite García y J. Grau Rebollo (2017): "La representación de la diversidad sociocultural en la publicidad televisiva de prime-time en España desde la óptica del alumnado universitario", en Temps d'Educació, 53, Barcelona: Universitat de Barcelona.

M. Marcos, J.J. Igartua, F.J. Frutos, I.M. Barrios, F. Ortegay V. Piñeiro (2014): "La representación de los personajes inmigrantes en los programas de ficción", en revista de comunicación Vivat Academia, 127. Madrid: Historia de los Sistemas Informativos y Fórum Internacional de Comunicación y Relaciones Públicas (Forum XXI), páginas 43 a 71; recuperado el 30 de abril de 2017, de http://www.vivatacademia.net/index.php/vivat/article/view/566/84.

M. Marcos Ramos y J.J. Igartúa Perosanz (2014): “Análisis de las interacciones entre personajes inmigrantes/extranjeros y nacionales/autóctonos en la ficción televisiva española", en Anuario Electrónico de Estudios en Comunicación Social «Disertaciones», 7(2). San Cristóbal (Venezuela): Universidad de Los Andes, páginas 136 a 159; recuperado el 25 de marzo de 2017, de http://revistas.urosario.edu.co/index.php/disertaciones/article/view/3737

R. Martínez Corcuera (2005): Interculturalidad y publicidad. Mugak, 30. Donostia (España): SOS Racismo de Guipúzcoa, páginas 1 a 11, recuperado el 20 de septiembre de 2017, de http://www.mugak.eu/revista-mugak/no-30/interculturalidad-y-publicidad

B.M. Mazzara (1999): Estereotipos y prejuicio. Madrid: Acento.

M.Miles y M. Huberman (1994): Qualitative data analysis. London: Sage.

P. Martínez (2008): Cualitativa-mente. Los secretos de la investigación cualitativa. Madrid: MillwardBrowm, ESIC.

G. Millerson (1993): Técnicas de realización y producción en televisión. Madrid: IORT.

E. Muraca (2013): Diseño y comunicación de la pluralidad sociocultural en las sintonías musicales de los teleinformativos. Universitat Autònoma de Barcelona.

E. Muraca (2012). Música, Telenoticias y Comunicación Intercultural. Tesis doctoral en curso, dirigida por Nicolás Lorite García. Universitat Autónoma de Barcelona.

J.L. Ruiz Olabuénaga (2012): Metodología de la investigación cualitativa $5^{\text {a }}$ edición., Bilbao: Universidad de Deusto.

J.C. Sendín y P. Izquierdo (2008): Guía práctica para los profesionales de los medios de comunicación. Tratamiento mediático de la inmigración. Madrid: OBERAXE; recuperado el 25 de noviembre de 2017, de http://www.harresiakapurtuz.org/wp-content/uploads/2016/03/Gu\%C3\%ADapr\%C3\%A1ctica tratamiento-medi\%C3\%A1tico-de-la-inmigraci\%C3\%B3n.pdf.

S. Shankar (2015): Advertising Diversity: Ad Agencies and the Creation of Asian American 
RLCS, Revista Latina de Comunicación Social, 73 - Páginas 425 a 446 [Investigación] [Financiada] DOI: 10.4185/RLCS, 73-2018-1263| ISSN 1138-5820| Año 2018

Consumers. Durham, NC: Duke University Press.

W. Sheldon (1954): Atlas of Men. A guide for somatotyping the adult male at all ages. University of Michigan: Harper.

Cómo citar este artículo / Referencia normalizada

N Lorite García, J Grau Rebollo, J de Sousa Lacerda (2018): "Representación de la diversidad sociocultural en la publicidad audiovisual: materiales para un tratamiento inclusivo". Revista Latina de Comunicación Social, 73 , pp. 425 a 446.

http://www.revistalatinacs.org/073paper/1263/22es.html

DOI: $10.4185 /$ RLCS-2018-1263

- En el interior de un texto:

...N Lorite García, J Grau Rebollo, J de Sousa Lacerda (2018: 425 a 446) ...

$\mathrm{O}$

... N Lorite García et al, 2018 (425 a 446) ...

Artículo recibido el 31 de noviembre de 2017. Aceptado el 14 de febrero. Publicado el 22 de febrero de 2018 